\title{
Human rights and psychiatry
}

\author{
Rosalind Ramsay, Senior Registrar in Psychiatry, Farnborough Hospital, \\ Farnborough Common, Orpington, Kent BR6 8ND
}

Physicians for Human Rights (PHR UK) is an independent group of doctors and health professionals launched two years ago by Drs Ian Munroe, former editor of the Lancet and Peter Kandela, a Middlesex GP. The group's aim is to direct the influence of the medical profession towards the defence of human rights, most immediately by bringing the skills of the medical profession to the aid of victims of human rights abuses (Hall, 1991).

For the individual practitioner, such an admirable objective may seem a tall order, but if doctors in a professional group work together to achieve a common goal, they can be a very powerful lobby for change. At PHR's second annual meeting, held in London in October 1991, speakers addressed different issues in the interplay of medicine and human rights. Lawyer and human rights activist, $\mathrm{Dr}$ Francoise Hampson, who looked at what doctors could actually be doing, singled out the Royal College of Psychiatrists for special praise over the effectiveness of its efforts to focus attention on the widespread abuse of psychiatry in the pre-glasnost USSR and so act as an impetus for change. Drawing on this example, Hampson emphasised the need for professional solidarity between doctors in different countries. For the individual practitioner, she believed there was scope for 'medical detective' work if doctors could use their forensic and diagnostic skills in making objective assessments of victims of alleged torture and also in offering survivors psychosocial and physical treatment. BBC foreign correspondent, Charles Wheeler, added another side to the story as he made a plea for increased cooperation between journalists and both the medical and legal professions.

PHR are reaching out to countries where there have been human rights abuses reported and over the last two years have sent special missions to investigate the situations in Kashmir, Kuwait, South Africa and Yugoslavia. They are also building up a network of supporters in this country. At present their membership is small but eminent with 48 of the 218 members University Professors, and including a number from psychiatry. If you are interested in finding out more about the group, contact the Secretariat, c/o University Department of Forensic Medicine, The Royal Infirmary, Dundee DD1 9ND, telephone 0382 200794, fax 038222094.

\section{Reference}

Hall, P. (1991) Physicians for Human Rights (UK). BMJ, $303,1562-1563$.

\section{People and places}

\section{Natalie Cobbing Travel Fellowship}

\section{BAMBRICK, Senior Lecturer in Mental Handicap, Department of Mental Handicap, Queen's Medical Centre, Nottingham NG7 2UH and Aston Hall, Aston-on-Trent, Derbyshire}

In 1987-88 I undertook a research project, to look at parental views on sterilisation for their mentally handicapped offspring. This project was prompted by the then recent decision of the High Court in the UK, which authorised the sterilisation of a 17-year- old girl with mental handicap, and created much controversy and debate at the time. Very little was known about the views of parents as a group in the UK on this issue, and hence the decision of our Department of Mental Handicap in Nottingham 
to explore this area (Bambrick \& Roberts, in press).

While engaged in this project, with encouragement from Professor G. E. Roberts, I applied for, and was awarded, the Natalie Cobbing Travelling Fellowship on the basis of the research topic and my proposal to use the money to spend some time at the Hastings Centre. The centre is a bioethics institute in the USA and is engaged in the study of ethical and moral issues that arise in medicine and the life-sciences. It had, in 1976, undertaken a project to examine the ethical, moral and legal dimensions of sterilisation (Macklin \& Gaylin, 1981), and it seemed an appropriate place to visit in connection with this research interest. With some creative accounting, I also incorporated a visit to a mental handicap service in Westchester County, New York, and a trip to Bangkok later in the year, to the 9th Asian Conference on Mental Retardation.

I proposed to concentrate on ethical issues surrounding sterilisation and 'who should decide' in the nexus of health care providers/parents/mentally handicapped patients during my stay at the Centre.

\section{The Hastings Centre}

The Hastings Centre was established in Hastings-onHudson in New York in 1969, but has recently moved to Briarcliffe Manor, a small village in Westchester County, New York. The co-founders, Daniel Callahan, a philosopher, and Willard Gaylin, a psychiatrist, considered there was a need for an institute to do systematic studies of bioethical issues at a time when difficult moral dilemmas were increasingly surfacing with new technology and advances in medicine and science. Today the Hastings Centre, with The Kennedy Institute of Ethics in Washington, are considered the pre-eminent institutes engaged in the field of bioethics in the USA. When the institute started, issues relating to artificial respiration, heart transplantation and pre-natal diagnosis were to the fore. Twenty years on, and an explosion in technological advances, e.g. genetic engineering and in vitro fertilisation, as well as issues such as AIDS and health care cost containment, have generated further ethical dilemmas.

The Centre is committed to non-partisan and interdisciplinary research, to education and consultation on ethical problems arising from advances in medicine, biology and the professions. Projects of one to three years duration are undertaken by multidisciplinary groups, consisting of centre staff and outside participants, which are set up to tackle a particular set of problem. The Hastings Centre staff include philosophers, a physician, a theologian and a lawyer. Results of a project may be a set of ethical guidelines for practitioners, a public policy report or a volume of theoretical essays. The centre's guidelines on the definition of death has been adopted by 13 US states. It has drawn up guidelines on confidentiality in AIDS research and use of HIV antibody tests, and have published guidelines on the termination of life-sustaining treatment. Projects ongoing at the time of my visit included AIDS and the ethics of patient care; the ethics of assisted reproduction; and the ethics of animal experimentation.

\section{Hastings Centre visit}

I arrived in New York at the end of August and had allowed myself four days to acclimatise and to do some sightseeing before travelling on to Briarcliffe Manor, about an hour's train journey away. The low point of the trip came the night before leaving for the Hastings Centre as I sat in my room puzzling over what deonological and teleogical theories were, and asking myself, "What am I doing here?"

The two weeks I spent were fascinating and challenging. Mornings were spent either reading or having discussions with the other two visiting scholars. These were a physician and a prospective lawyer who were looking at the ethics of cost containment, diagnostic related groups in health care, and the making of living wills.

Lunch was in-house at the Centre and was a forum for impromptu debate and discussion with the Centre's associates. These ranged from decisionmaking on withdrawing or withholding treatments in neonatal intensive care to the other end of life and its prolongation by artificial nutrition and hydration. During my first week I made a lunch-time presentation, outlining the topic I was to work on during my stay. I did this to a helpful but challenging audience. I had also the opportunity for individual discussion with several of the Centre staff, which helped clarify the various strands to be examined in the issue of sterilisation for people with mental handicap-whether it is morally justified; what should be the procedures for choosing surrogate decision-makers; who should they be and the principles of ethical judgement they should follow; who is best placed to decide the 'best interest' of an incompetent individual; how easy or otherwise is it to separate the family interests as being irrelevant in decision-making, when it may not be so easy to detach the life of the person with mental handicap from the lives of those close to and caring for him/her?

I found that there were no easy answers to these questions lying within the covers of the large collection of books in their library. What I did find, however, was that the field of bioethics can aid in bringing greater clarity to a problem, even when final answers are elusive. In the field of mental handicap, working with a population whose power of self-determination is limited to greater or lesser degree, one is confronted with many decisions that have to be made on behalf of the handicapped person. These are not 
the headline-catching dramas of sterilisation, but decisions which may have a profound impact on the life of the person, decisions about where he/she will live and whom he/she will live with being but one example. My time at the Hastings Centre left me a lot more thoughtful and certainly a lot more uncomfortable. The bioethicists would count that a successful outcome!

\section{Westchester Mental Retardation Institute}

During my visit to the USA I also spent four days looking at some of the mental handicap services. I was able to do this with the help of the Mental Retardation Institute (MRI) at Westchester County Medical Centre, Valhalla, New York. The MRI is a University Affiliated Facility (UAF) of which there are 49 throughout the USA. They developed out of some of the recommendations of the President's Panel on Mental Retardation (1962), which was established to examine services for people with mental handicap and other developmental disabilities. The stated mission of the UAFs is to support the independence, productivity and integration into the community of people with mental handicaps. This is accomplished through the training of professionals in the field, through creating model service programmes and helping local and State agencies replicate these programmes, through ongoing research and sharing of information gained with a broad audience.

The MRI is primarily affiliated with New York Medical College. It provides, in co-operation with a large number of other local and state services, a range of services for mentally handicapped people and their families. It has out-patient clinical services which provide diagnosis, evaluation, treatment and consultation by staff representing a number of medical specialities (many on a sessional basis from the on-site hospital complex), and a wide variety of other disciplines. I sat in on one of their multidisciplinary adult referral meetings, at which referrals are discussed, appropriate assessments are commissioned; this always includes a medical assessment by their general practice-trained staff doctor. On completion of these a case conference is held to make decisions on management/treatment.

I was able to spend some time with the Director of the Developmental Disabilities Services for Westchester County, who valiantly tried to explain to me the complexities of funding and the many different service providers operating in the county. One of these service providers - the Westchester Association for Retarded Citizens - allowed me to visit their sheltered workshop. The Association also provides vocational services in the form of supported work, training centres which have supervised contract work, and supports some individuals in open employment, assigning them a job coach in the initial stages to facilitate adaptation.
People with mental handicap who present with challenging behaviours or psychiatric disorder, may be seen by one of a number of different services in the county. The Developmental Disabilities Service Office have a Behavioural Consultation Unit which provides advice, behavioural strategies and staff training in the person's normal setting. The Retarded Citizen's Association has a crisis intervention project of their own, and the mobile crisis intervention service (which is part of the general psychiatric service) may be used. People with mental handicap who have psychiatric disorder may be admitted on a short-term basis to the general psychiatric hospital. I was not clear how much these services either overlap or complement each other.

With still some change in my pocket, I headed off to Thailand at the beginning of November 1989 to attend the 9th Asian Conference on Mental Retardation in Bangkok. The theme was quality of life for the mentally retarded. I presented my paper on parental views on sterilisation at a session on legal and social support for the mentally retarded. Once that was out of the way I settled down to enjoy the conference. The most interesting part was meeting a lot of people working in the field of mental handicap in very different economic and cultural settings. The most memorable would have to be the two nuns who worked in a refugee camp on the Thai-Laos border and were doing heroic work with people with both mental and physical handicaps, in very difficult conditions.

All the delegates at the conference were given the opportunity to visit some facilities for people with mental handicap. I visited a day centre for young children, and also a centre for adults. One of the major problems faced by these facilities was transport. The traffic jams in Bangkok are horrendous and many parents do not relish the prospect of a possible two-hour journey each way. No social services transport here to ease the burden, either for themselves or their child.

Finally, I did not feel that my research would be complete until I found out who Natalie Cobbing was. Miss Natalie Cobbing was Secretary of the Royal Medical-Psychological Association and the Royal College of Psychiatrists from 1958 until her death in 1984. In her will she left a substantial amount of money to be used in the field of mental handicap. It was the Royal College of Psychiatrists Council's decision to create the Natalie Cobbing Fellowship to further the training of specialists in the psychiatry of mental handicap by enabling them to extend their experience with travel to appropriate centres overseas.

\section{References}

BAMBRICK, M.\& RoberTS, G. E. Sterilisation of people with mental handicap: the views of parents. Journal of Mental Deficiency Research (in press).

Macklin, R. \& Gaylin, W. (eds) (1981) Mental Retardation and Sterilisation. New York: Plenum Press. 